\begin{tabular}{|c|c|c|}
\hline $\begin{array}{l}\text { PKS } \\
\text { PUBLIC } \\
\text { KNDWLDEG } \\
\text { PROJECT }\end{array}$ & $\begin{array}{c}\text { REVISTA DE GEOGRAFIA } \\
\text { (RECIFE) } \\
\text { http://www.rvista.ufpe.br/revistageografia }\end{array}$ & $\begin{array}{l}\text { OJS } \\
\frac{\text { OPEN }}{\text { JOUNAL }} \\
\text { SYSTEMS }\end{array}$ \\
\hline
\end{tabular}

\title{
O SETOR PORTUÁRIO DE SERGIPE: REDES, FLUXOS E PARTICIPAÇÃO DO CAPITAL PRIVADO
}

\author{
Nelson Fernandes Felipe Junior ${ }^{1}$ \\ ${ }^{1}$ Docente do Departamento de Geografia e do Programa de Pós-graduação em Geografia. Universidade \\ Federal de Sergipe -UFS. E-mail: nelfelipejr@hotmail.com \\ Artigo recebido em 04/07/2017 e aceito em 07/12/2018

\begin{abstract}
RESUMO
O transporte marítimo contribui com o escoamento de mercadorias no espaço e permite articular diferentes regiões e países, sendo importante para o desenvolvimento econômico. Sergipe apresentou maior inserção econômica em âmbito regional e nacional na última década, todavia, possui um setor portuário pouco dinâmico que prejudica os fluxos, as redes e o efeito multiplicador interno. Diante desse contexto, busca-se realizar uma análise setorial e, em especial, do Terminal Marítimo Inácio Barbosa (TMIB), localizado no município de Barra dos Coqueiros/SE.
\end{abstract} \\ Palavras-chave: setor portuário; transporte marítimo; desenvolvimento econômico.
}

\section{THE PORT SECTOR OF SERGIPE: NETWORKS, FLOWS AND PARTICIPATION OF PRIVATE CAPITAL}

\begin{abstract}
Shipping contributes to the flow of goods in space and allows articulate different regions and countries, is important for economic development. Sergipe presented greater economic integration at the regional and national levels over the past decade, however, has a little dynamic port sector that affect the flows, the networks and the internal multiplier effect. In this context, we seek to carry out a sectoral analysis and in particular the Maritime Terminal Inácio Barbosa (TMIB), located in county Barra dos Coqueiros/SE.
\end{abstract}

Keywords: port sector; maritime transportation; economic development. 


\section{INTRODUÇÃO}

O transporte marítimo não representa um fim em si mesmo, ou seja, é um meio de servir a outros objetivos e outras demandas. A atividade produtiva é, em parte, dependente do transporte marítimo para conquistar mercados externos (acumulação e reprodução do capital), ao passo que a cabotagem tem como objetivo principal subsidiar a cadeia de suprimentos interna. O sistema de transportes e, em especial, o modal marítimo é, por um lado, um reflexo da economia regional/nacional e, por outro, um fator que impulsiona o desenvolvimento. $\mathrm{O}$ transporte marítimo de cargas é subsidiário à produção e, ao mesmo tempo, importante para completar a rotatividade do capital.

A modernização do sistema de transportes facilita a mobilidade e a acessibilidade e reduz o tempo de deslocamento no espaço. A participação do Estado é fundamental para o desenvolvimento econômico, para o fomento do transporte marítimo e para a circulação do capital. A partir de políticas setoriais, fiscais, monetárias, cambiais e de estímulo ao crédito, o poder público influencia a distribuição dos fatores de produção no território, ao mesmo tempo em que se intensifica o consumo interno, as exportações, as importações e a movimentação de navios cargueiros e contêineres.

Os portos, os terminais privados, o transporte marítimo e as estratégias logísticas exercem influência na movimentação de cargas e na circulação do capital. Quanto mais rapidamente circula o capital, ou seja, quanto maior é a sua velocidade de rotação, menor é a estocagem de cargas e maior é a acumulação. Portos e terminais modernos atraem mercadorias de importação e exportação, gerando reflexos macroeconômicos positivos em âmbito regional.

Com a reestruturação produtiva, as tecnologias ligadas à circulação, a grande capacidade dos navios cargueiros e a otimização logística, têm-se intensas repercussões na produção e no comércio. Grandes quantidades de cargas, atualmente, podem ser transportadas em menos tempo e com custos mais baixos, aparecendo sucessivamente no mercado (reabastecimento rápido do estoque), não sendo necessário, portanto, a armazenagem em larga escala na forma de capital-mercadoria latente.

Apesar das condições naturais existentes, a cabotagem é pouco utilizada em Sergipe e no Brasil. O transporte marítimo de longo curso (internacional), por sua vez, é responsável 
por grande parte das compras e vendas externas do país - em 2015, as exportações via marítima representaram $96 \%$ do total e as importações $89 \%$.

Diante disso, busca-se analisar a participação do capital privado a partir da década de 1990 e os principais gargalos que prejudicam o setor portuário de Sergipe, gerando impactos na economia, na sociedade, na geração de empregos e renda e no desenvolvimento regional.

\section{INFRAESTRUTURAS PORTUÁRIAS, CIRCUlaÇÃO DO CAPITAL E DESENVOLVIMENTO ECONÔMICO}

Ao reduzir o tempo gasto na circulação, aumenta-se a velocidade da reprodução do capital, o funcionamento dos meios de produção será potencializado, eleva-se a produtividade e há incremento na extração de mais-valia (MARX, 2005). Os avanços ligados ao setor portuário e ao transporte marítimo (logística, comunicações, instalações e tecnologias) permitem o escoamento de cargas em menos tempo e com maior segurança, por conseguinte, há baixo risco de perda dos produtos, prejuízo por parte dos produtores e atraso na entrega dos bens.

O Estado possui função relevante no que tange ao incremento (ou não) do processo de circulação do capital e de desenvolvimento econômico, já que a expansão das infraestruturas de transporte, comunicação e energia (destaque para o fomento da intermodalidade, dos portos e do transporte marítimo), as políticas setoriais e outros, são importantes para acelerar a rotatividade do capital e satisfazer as demandas econômicas e sociais (RANGEL, 2005).

Através das inversões estatais, o poder público condiciona os investimentos privados de duas formas: a) imediatamente: é resultado dos atrativos gerados a partir dos investimentos em infraestruturas (transportes, energia etc.), sendo representado pelos investimentos produtivos; b) indiretamente: pela ação que seus gastos, mais os gastos privados, exercem sobre a demanda. A influência sobre a demanda total (inversões, reinvestimentos e consumo) é acelerada e se multiplica (RANGEL, 2005). Assim, por exemplo, quando há investimentos em um porto, estimulam-se as inversões do capital privado e, consequentemente, são gerados empregos e renda regionalmente.

O sistema portuário e marítimo brasileiro é caracterizado pela desregulamentação, bem como pela existência de oligopólio estrangeiro, sendo intensificado pela legislação neoliberal criada na década de 1990 (Lei 8.630/93 - Lei dos Portos), mitigando a reserva de mercado para os armadores nacionais e abrindo o setor para o grande capital estrangeiro. Os 
principais armadores que atuam nos portos e terminais do país são: Hamburg Süd (Alemanha), Maersk (Dinamarca), Mediterranean Shipping Company (MSC) (Itália/Suíça), Aliança (pertence à Hamburg Süd, Alemanha), CMA/CGM (França), Mitsui/OSK Lines (Japão), Cosco (China), Evergreen (Taiwan), China Shipping (China) e Hyundai (Coreia do Sul).

A logística privada e as infraestruturas possuem uma relação de coexistência, contudo, possuem significados distintos. Em muitos casos, as estratégias logísticas atenuam os pontos de estrangulamento existentes no sistema de transportes, sem que isso represente melhorias nos fixos. Assim, adotar novas rotas - mais curtas, com maior fluidez e com melhores condições de tráfego e sinalização - influencia os custos de transporte e garante maior segurança às mercadorias.

A recuperação da economia brasileira, entre 2003 e 2013, impulsionou a movimentação portuária e marítima (demandas produtivas e consumo humano). De acordo com Rangel (2005), o crescimento da economia nacional assegura uma demanda potencial interna, impulsionada, sobretudo, pela geração de empregos na indústria, na construção civil, no comércio e nos serviços.

Houve, principalmente entre 2003 e 2013, a expansão das relações Sul-Sul (periferiaperiferia), com destaque às parcerias comerciais estabelecidas do Brasil com países da África (Egito, Angola, Moçambique etc.), do Oriente-Médio (Irã), do Leste Asiático (China e Índia, principalmente), do Leste Europeu (Polônia, Bulgária etc.), da América Latina (Peru, Venezuela, Cuba e outros), além de valorizar o Mercosul para o desenvolvimento do Brasil e das demais nações. Essa estratégia possuiu dois aspectos relevantes, quais sejam: a) indicou uma postura anti-imperialista (diante dos Estados Unidos); b) permitiu amenizar os impactos negativos da crise econômica internacional de 2008 no país.

A maior diversificação das parcerias comerciais gerou reflexos no transporte marítimo e no setor portuário nacional, com aumento da demanda por inversões em infraestruturas, maior movimentação de cargas, contêineres e navios nos portos brasileiros, modernização (investimentos em instalações, equipamentos e softwares) e outros. Os principais portos e terminais privados do Brasil possuem muitas linhas com os mais importantes portos do mundo, como Xangai (China), Cingapura e Roterdã (Holanda).

A expansão do transporte marítimo, da indústria naval e dos investimentos em infraestruturas portuárias, com aquisição de insumos e equipamentos nacionais, é uma importante estratégia para alavancar a produção brasileira e, consequentemente, o 
desenvolvimento econômico. Nesse sentido, é relevante uma política econômica que estimule a cabotagem e o longo curso no país, com base no crédito a juros baixos, nos subsídios estatais ao setor, na reserva de mercado e outros.

A construção de infraestruturas, sobretudo nas regiões menos dinâmicas, é imprescindível ao desenvolvimento nacional, gerando repercussões positivas na economia, na sociedade e nas interações espaciais. O Estado - a partir do planejamento e dos investimentos - tem a responsabilidade de reduzir as desigualdades inter-regionais e estimular a distribuição de renda no país, especialmente nas regiões Norte e Nordeste (RANGEL, 2005).

No caso de Sergipe e do Brasil há um predomínio das estratégias logísticas de otimização do deslocamento no espaço sem haver alterações na malha viária, ou seja, ocorrem, por exemplo, mudanças de rotas e percursos, todavia, as deficiências infraestruturais permanecem intensas no território. Ainda que avanços relativos tenham ocorrido na última década, ainda são insuficientes as inversões públicas e privadas no setor de transportes em Sergipe, principalmente no que tange à intermodalidade (tabela 1).

Tabela 1: Participação dos modais no transporte de cargas em Sergipe, 2015 (porcentagem).

\begin{tabular}{c|c}
\hline Modais & Total \\
\hline Rodoviário & 88,7 \\
\hline Ferroviário & - \\
\hline Hidroviário & 6,2 \\
\hline Outros & 5,1 \\
\hline
\end{tabular}

Fonte: Ministério dos Transportes, 2016.

Há um grande predomínio do modal rodoviário no transporte de cargas em Sergipe (tabela 1). O processo de desenvolvimento foi subsidiado pelo escoamento das mercadorias através de caminhões. No estado de Sergipe houve, sobretudo a partir da década de 1970, um sucateamento do modal ferroviário e uma concentração exacerbada dos fluxos nas rodovias.

Existe uma contradição no contexto econômico sergipano e brasileiro, qual seja: por um lado, há a valorização das exportações de commodities e, por outro, a deterioração de parte das infraestruturas de transportes (apesar dos investimentos recentes do Governo Federal, do Governo Estadual e do Programa de Aceleração do Crescimento - PAC). O escoamento de mercadorias, muitas vezes, ocorre a partir de vias precárias e de infraestruturas obsoletas. Diante disso, é necessário aumentar a participação dos modais ferroviário e hidroviário no transporte de produtos em Sergipe e no Brasil. 
O transporte possui a função de satisfazer as demandas corporativas e humanas e agrega valor às mercadorias. O sistema de transportes e, em especial, o modal marítimo é fundamental para completar o ciclo de rotação do capital, visto que os produtores de bens primários e industriais dependem dos meios e das vias para escoamento das mercadorias dos centros de produção até os mercados consumidores. Os portos, os terminais e o transporte marítimo são resultantes da combinação dos fatores naturais (curso fluvial/mar/oceano), econômicos (produção, distribuição e demanda), políticos (investimentos, financiamentos, subsídios etc.) e humanos (consumo).

No que tange ao Terminal Marítimo Inácio Barbosa (TMIB), localizado no município de Barra dos Coqueiros/SE, este deve ser entendido como um complexo intermodal e componente (nó) da cadeia de distribuição internacional de mercadorias. A expansão dos portos públicos e dos terminais privados (caso do TMIB) gera reflexos na produção, no comércio, nos serviços e na geração de empregos e renda.

A formação de redes marítimas (cabotagem e longo curso) é basilar para o processo de reprodução do capital. O tempo de rotação do capital é acelerado com a otimização do sistema de transportes e, em especial, do modal marítimo, mediante a utilização de navios e contêineres modernos, rapidez e eficiência no transbordo das cargas, vias de acesso fluidas aos portos, utilização da intermodalidade, grande profundidade para atracação de navios cargueiros etc. A expansão do setor portuário e do transporte marítimo é essencial para fomentar o comércio exterior, as trocas inter-regionais, a produção, os serviços e o desenvolvimento regional.

As obras do PAC 1 e PAC 2 para melhoria do sistema marítimo brasileiro se concentraram na adequação e na expansão das instalações já existentes (e não na construção de novos portos). O PAC-portos realizou um investimento total de 7,5 bilhões de reais. Deste montante, 2,4 bilhões de reais foram aplicados entre 2007 e 2010 (PAC-portos 1) e 5,1 bilhões de reais investidos entre 2011 e 2014 (PAC-portos 2) (quadro 1).

Quadro 1: Obras do PAC 1 e PAC 2 no setor portuário brasileiro.

\begin{tabular}{|c|c|c|c|}
\hline \multicolumn{2}{|c|}{ PAC 1 } & \multicolumn{2}{c|}{ PAC 2 } \\
\hline Portos & Obras & Portos & Obras \\
\hline \multirow{3}{*}{$\begin{array}{c}\text { Vila do } \\
\text { Conde/PA }\end{array}$} & $\begin{array}{c}\text { Ampliação do píer } \\
\text { principal }\end{array}$ & Santarém/PA & $\begin{array}{c}\text { Ampliação do terminal de uso } \\
\text { múltiplo } \\
1\end{array}$ \\
& & & $\begin{array}{c}\text { Construção do terminal de uso } \\
\text { múltiplo 2 }\end{array}$ \\
\cline { 2 - 4 } & Rampas roll on, roll & Manaus/AM & Construção do terminal de \\
\hline Felipe Junior, 2018.
\end{tabular}




\begin{tabular}{|c|c|c|c|}
\hline & off & & passageiros \\
\hline & $\begin{array}{l}\text { Construção do } \\
\text { terminal de uso } \\
\text { múltiplo }\end{array}$ & $\begin{array}{c}\text { Luís } \\
\text { Correia/CE }\end{array}$ & Dragagem \\
\hline \multirow{4}{*}{ Itaqui/MA } & \multirow{2}{*}{$\begin{array}{c}\text { Construção dos berços } \\
100 \\
\text { e } 108\end{array}$} & \multirow[t]{2}{*}{ Fortaleza/CE } & $\begin{array}{l}\text { Construção do terminal de } \\
\text { contêineres }\end{array}$ \\
\hline & & & $\begin{array}{l}\text { Construção do terminal de } \\
\text { passageiros }\end{array}$ \\
\hline & $\begin{array}{l}\text { Recuperação dos } \\
\text { berços } 101 \text { e } 102 \\
\end{array}$ & $\begin{array}{c}\text { Areia } \\
\text { Branca/RN } \\
\end{array}$ & Dragagem \\
\hline & Dragagem & \multirow[t]{2}{*}{ Natal/RN } & Ampliação do cais \\
\hline $\begin{array}{c}\text { Areia } \\
\text { Branca/RN }\end{array}$ & Ampliação & & $\begin{array}{l}\text { Construção do terminal de } \\
\text { passageiros }\end{array}$ \\
\hline Natal/RN & Dragagem & Recife/PE & $\begin{array}{l}\text { Construção do terminal de } \\
\text { passageiros }\end{array}$ \\
\hline $\begin{array}{c}\text { Luís } \\
\text { Correia/CE }\end{array}$ & $\begin{array}{c}\text { Conclusão da } \\
\text { construção do porto }\end{array}$ & Maceió/AL & Dragagem \\
\hline Fortaleza/CE & Dragagem & Suape/PE & $\begin{array}{l}\text { Construção do terminal de } \\
\text { granéis sólidos }\end{array}$ \\
\hline Recife/PE & Dragagem & \multirow[t]{2}{*}{ Salvador/BA } & Ampliação do quebra-mar \\
\hline Cabedelo/PB & Dragagem & & $\begin{array}{l}\text { Construção do terminal de } \\
\text { passageiros }\end{array}$ \\
\hline \multirow[t]{2}{*}{ Suape/PE } & Dragagem & $\begin{array}{l}\text { Barra do } \\
\text { Riacho/ES }\end{array}$ & Dragagem \\
\hline & $\begin{array}{l}\text { Construção do acesso } \\
\text { rodo-ferroviário }\end{array}$ & \multirow{3}{*}{ Vitória/ES } & Construção de mais um berço \\
\hline Salvador/BA & Dragagem & & $\begin{array}{c}\text { Construção do pátio de } \\
\text { estocagem }\end{array}$ \\
\hline Maceió/AL & $\begin{array}{c}\text { Construção do cais de } \\
\text { contêineres }\end{array}$ & & $\begin{array}{c}\text { Aprofundamento da área } \\
\text { portuária }\end{array}$ \\
\hline Aratu/BA & Dragagem & $\begin{array}{l}\text { Barra do } \\
\text { Furado/RJ }\end{array}$ & Dragagem \\
\hline \multirow[t]{2}{*}{ Vitória/ES } & Ampliação do cais & \multirow{4}{*}{$\begin{array}{c}\text { Rio de } \\
\text { Janeiro/RJ }\end{array}$} & Proteção e reforço do cais \\
\hline & Dragagem & & Dragagem \\
\hline $\begin{array}{c}\text { Rio de } \\
\text { Janeiro/RJ }\end{array}$ & Dragagem & & Construção de novos píeres \\
\hline $\begin{array}{l}\text { Angra dos } \\
\text { Reis/RJ }\end{array}$ & Dragagem & & $\begin{array}{l}\text { Construção do terminal de } \\
\text { passageiros }\end{array}$ \\
\hline Itaguaí/RJ & Dragagem & Itaguaí/RJ & Dragagem \\
\hline \multirow{3}{*}{ Santos/SP } & Dragagem & \multirow{5}{*}{ Santos/SP } & Avenida perimetral \\
\hline & Expansão de áreas & & $\begin{array}{c}\text { Construção dos píeres Alemoa e } \\
\text { Barnabé }\end{array}$ \\
\hline & Avenida perimetral & & Proteção e reforço do cais \\
\hline Paranaguá/PR & Dragagem & & Dragagem \\
\hline \multirow{2}{*}{$\begin{array}{c}\text { São Francisco } \\
\text { do Sul/SC }\end{array}$} & Dragagem & & Realinhamento do cais \\
\hline & Berços 101 e 201 & \multirow[t]{2}{*}{ Itajaí/SC } & Reforço do berço \\
\hline \multirow[t]{2}{*}{ Itajaí/SC } & Dragagem & & Retroárea \\
\hline & Ampliação do molhe & Imbituba/SC & Dragagem \\
\hline
\end{tabular}




\begin{tabular}{|l|c|c|c|}
\hline Rio Grande/RS & Dragagem & \multirow{2}{*}{$\begin{array}{c}\text { Rio } \\
\text { Grande/RS }\end{array}$} & $\begin{array}{c}\text { Construção do cais do Porto } \\
\text { Novo }\end{array}$ \\
\cline { 2 - 2 } & $\begin{array}{c}\text { Construção do cais do } \\
\text { Porto Novo }\end{array}$ & Dragagem \\
\hline
\end{tabular}

Fonte: Ministério do Planejamento - PAC-portos, 2015.

Em relação às obras do Programa de Aceleração do Crescimento (PAC) no estado de Sergipe (tabelas 2 e 3), destaca-se a duplicação da BR-101, sendo relevante para o aumento da fluidez, para as interações espaciais e para o efeito multiplicador interno. As concessões de trechos à Engenharia do Exército elucidam avanços nas obras em comparação às concessões a empresas privadas (principalmente em relação à rapidez e término das construções).

Tabela 2: Inversões do Programa de Aceleração do Crescimento (PAC) e do Programa Minha Casa, Minha Vida em Sergipe (2011-2014).

\begin{tabular}{c|c}
\hline PAC & Milhões de reais \\
\hline Transportes & 992,06 \\
\hline Energia & $4.399,02$ \\
\hline Urbano & 150,43 \\
\hline Outros & 625,68 \\
\hline Minha Casa, Minha Vida & $2.336,90$ \\
\hline Total & $\mathbf{8 . 5 0 4 , 0 8}$
\end{tabular}

Fonte: Ministério do Planejamento - PAC, 2015.

Tabela 3: Investimentos do Programa de Aceleração do Crescimento (PAC) no setor de transportes em Sergipe (2011-2014).

\begin{tabular}{c|c}
\hline Modais & Milhões de reais \\
\hline Rodovias & 987,86 \\
\hline Ferrovias & - \\
\hline Portos & - \\
\hline Hidrovias & - \\
\hline Aeroportos & - \\
\hline Equipamentos para rodovias vicinais & 4,20 \\
\hline Marinha mercante & - \\
\hline Total & $\mathbf{9 9 2 , 0 6}$ \\
\hline
\end{tabular}

Fonte: Ministério do Planejamento - PAC, 2015.

Importantes investimentos federais ocorreram em Sergipe, principalmente entre $2010 \mathrm{e}$ 2014, com o objetivo de qualificar os fixos no território (tabelas 2 e 3). A redução dos pontos de estrangulamento e a mitigação das desigualdades intra e inter-regionais demandam maiores inversões, sobretudo, nas regiões menos dinâmicas. Avanços, nesse sentido, foram observados na última década, visto que a expansão de obras e a aquisição de recursos públicos 
federais por estados e municípios, especialmente do Nordeste e do Norte do país, foram fundamentais para dinamizar relativamente espaços periféricos dentro do território brasileiro.

Entre 2011 e 2014, todas as inversões em transportes no estado de Sergipe se concentraram no modal rodoviário, assim, infere-se que as ferrovias e o setor portuário continuarão apresentando os gargalos que prejudicam a modernização setorial e o desenvolvimento regional. Fomentar a dinâmica portuária é essencial para impulsionar o efeito multiplicador interno, os fluxos de cabotagem e longo curso e as interações espaciais. Ademais, seria interessante estimular a indústria naval em Sergipe (estaleiros), gerando reflexos positivos no emprego e na renda. Há uma demanda potencial no estado, principalmente em relação às atividades da Petrobras (petróleo, gás natural e derivados).

\section{O SETOR PORTUÁrio de SERGIPE, O MODELO DE CONCESSÃo E O TERMINAL MARÍTIMO INÁCIO BARBOSA (TMIB)}

As concessões ligadas ao transporte marítimo de cargas refletem, em geral, a frágil atuação do poder público, das Companhias Docas, das Administrações Portuárias, da Agência Nacional de Transportes Aquaviários (ANTAQ) e da Secretaria de Portos (SEP) na imposição de metas às concessionárias de transporte marítimo e de terminais, investimentos a serem realizados, fiscalização, liberdade de concorrência (muitas vezes os grandes armadores e os operadores de terminais pressionam o poder público no sentido de evitar a atuação de novas empresas no setor), "cartelização" do preço do frete e oligopólio estrangeiro.

Ocorreram importantes transformações no transporte de cargas nas duas últimas décadas, tanto em relação às infraestruturas quanto à gestão logística e às operações. A maior integração econômica e comercial do Brasil a partir da década de 1990 gerou repercussões no setor marítimo nacional. A modernização portuária é relevante para atender as demandas internas e externas, com articulação entre os transportes, as comunicações e as informações. A incorporação de novas tecnologias (equipamentos, softwares etc.) aumentou a eficiência e a produtividade portuária.

A participação do capital privado no setor portuário fomentou a modernização setorial. Nos principais portos e terminais privados do país, destacam-se os Ship Loaders automatizados (dutos de sucção), STS (Ship to Shore Crane) (portêineres), RTG (Rubber Tyres Gantry) (transtêineres), MHC (Mobile Habour Crane) (guindastes), Reach Stackers (empilhadeiras), Terminal Tractors (veículos especiais para movimentar contêineres), 
softwares (Cosmos e Navys), scanners, contêineres especializados para cada tipo de mercadoria (granel sólido, granel líquido, frigoríficos etc.), navios Full Containers (conteineros), graneleiros e mistos (líquidos e sólidos) de grande capacidade, sistema ISPS Code (câmeras e controle de pessoas, veículos e cargas), entre outros.

O setor portuário de Sergipe possui capacidade antiociosa, limitando-se ao Terminal Marítimo Inácio Barbosa (TMIB). Trata-se de uma concessão da União à Companhia Vale do Rio Doce desde 1994, sendo articulado às rodovias SE-226 e BR-101. Atualmente, o TMIB movimenta cargas de baixo valor agregado, como madeira, coque, ureia, cimento, trigo, fertilizantes, petróleo e derivados etc. (imagens 1,2 e 3 e tabela 4).

Em 2014, iniciou-se no Terminal Marítimo Inácio Barbosa o consórcio liderado pela Valor Logística Integrada (VLI), sendo responsável pelo gerenciamento operacional e comercial no TMIB. A Vale do Rio Doce possui a maior parte das ações (38\% do total), além de outros parceiros, caso da japonesa Mitsui (que também detém ações da Vale) e da canadense Brookfield.

Imagem 1: Instalações do Terminal Marítimo Inácio Barbosa (TMIB), 2015.

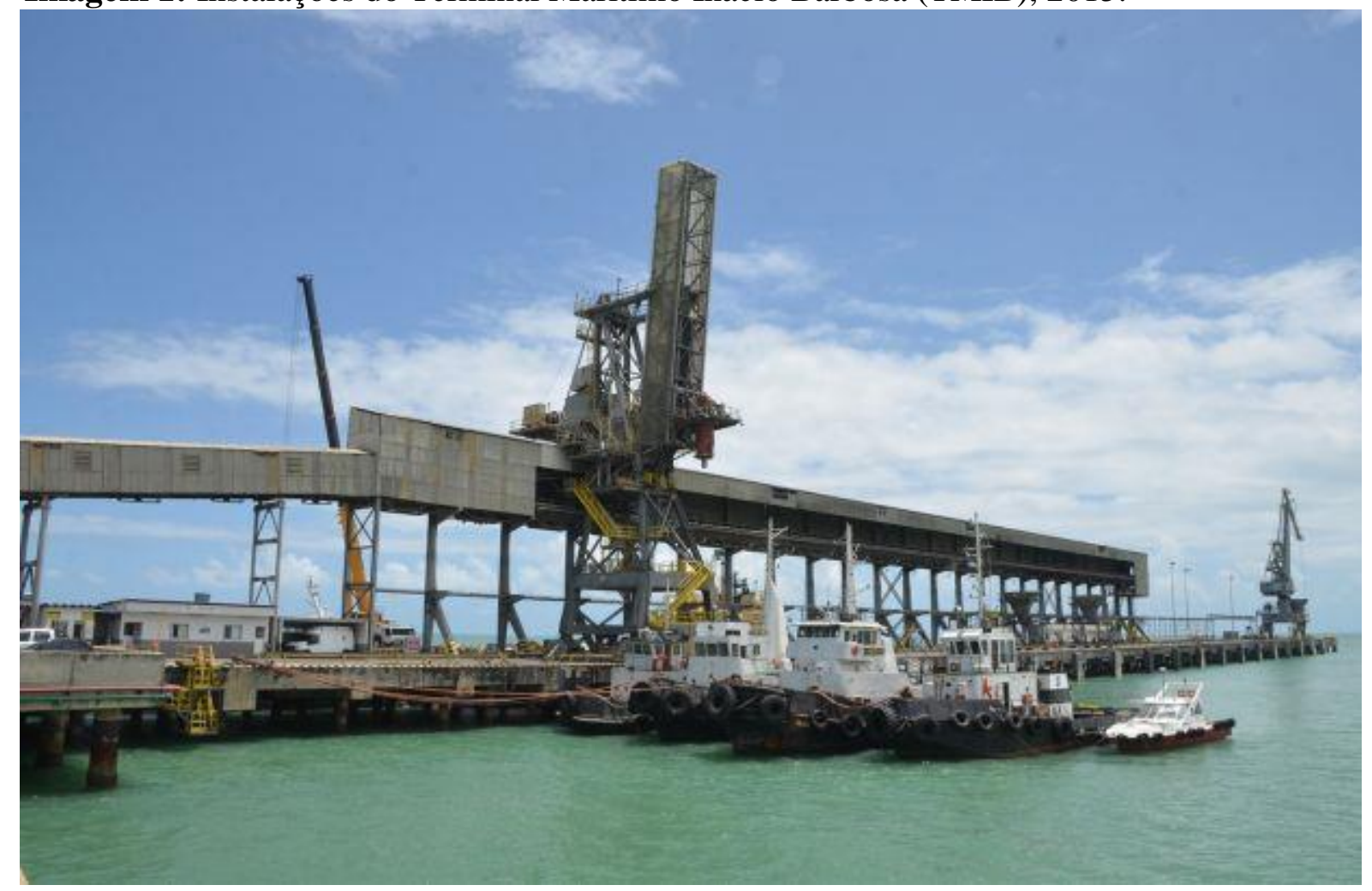

Fonte: Terminal Marítimo Inácio Barbosa (TMIB), 2015. 
Imagem 2: Navio atracado no Terminal Marítimo Inácio Barbosa (TMIB), 2015.

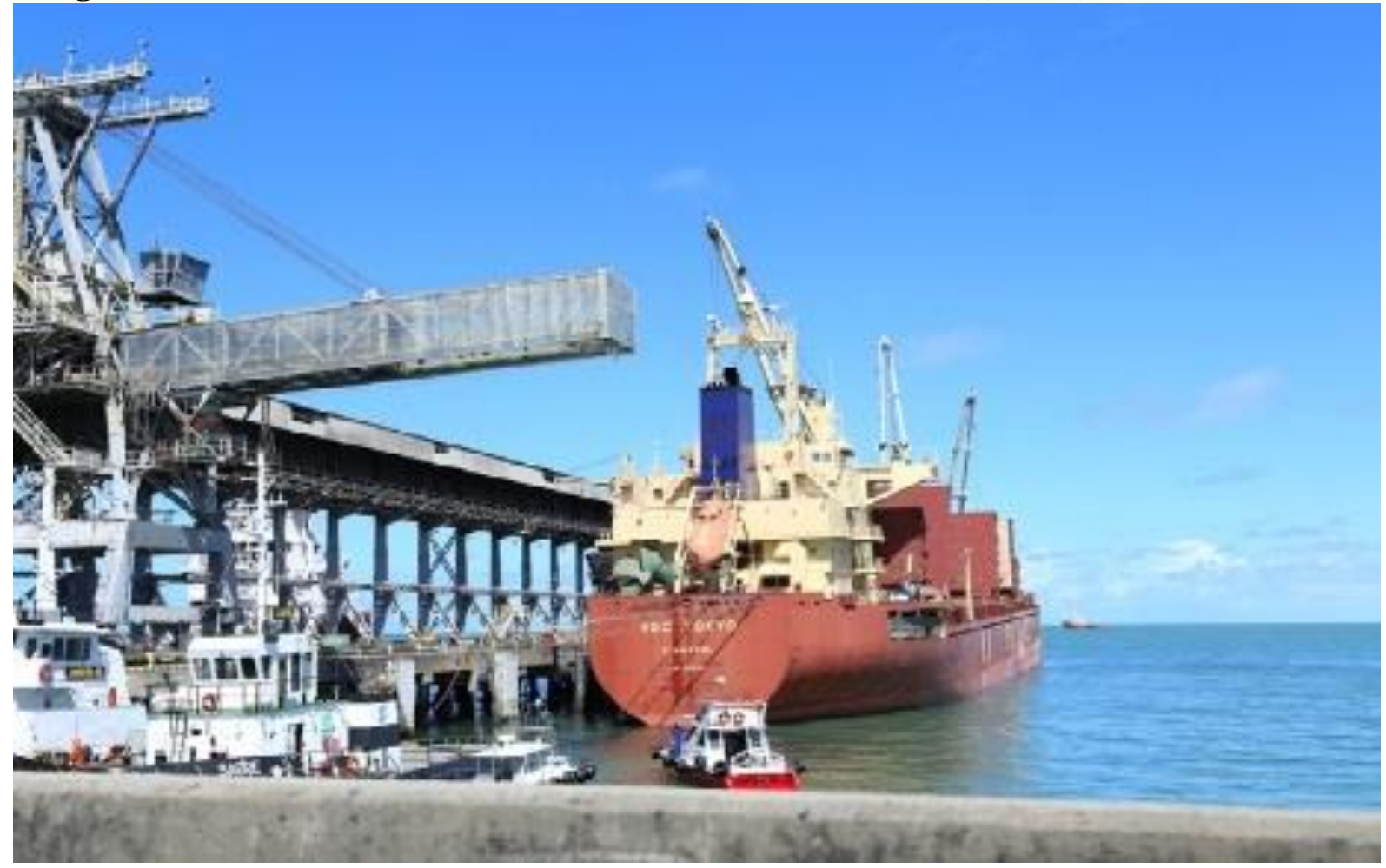

Fonte: Terminal Marítimo Inácio Barbosa (TMIB), 2015.

Imagem 3: Fiscalização da carga no Terminal Marítimo Inácio Barbosa (TMIB), 2015.

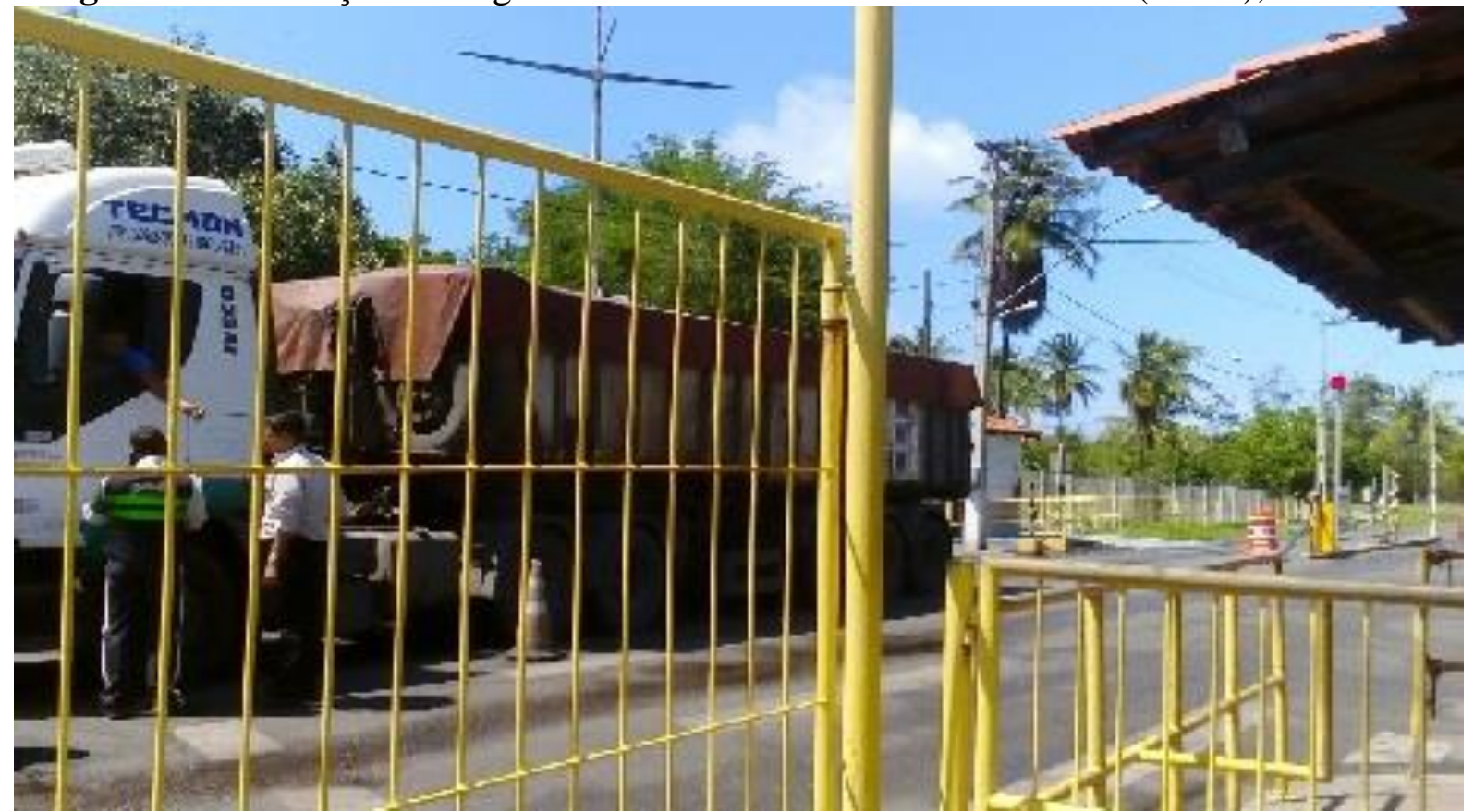

Fonte: Terminal Marítimo Inácio Barbosa (TMIB), 2015. 
Tabela 4: Movimentação total de cargas no Terminal Marítimo Inácio Barbosa (1995 e 20002014).

\begin{tabular}{c|c}
\hline Anos & Quantidade (toneladas) \\
\hline 1995 & 2.499 .800 \\
\hline 2000 & 2.757 .367 \\
\hline 2001 & 2.693 .501 \\
\hline 2002 & 2.886 .743 \\
\hline 2003 & 2.657 .452 \\
\hline 2004 & 2.059 .612 \\
\hline 2005 & 2.102 .871 \\
\hline 2006 & 2.776 .689 \\
\hline 2007 & 2.794 .255 \\
\hline 2008 & 2.500 .764 \\
\hline 2010 & 1.179 .484 \\
\hline 2011 & 885.558 \\
\hline 2012 & 896.035 \\
\hline 2013 & 1.837 .524 \\
\hline 2014 & 1.033 .652 \\
\hline
\end{tabular}

Fonte: Agência Nacional de Transportes Aquaviários (ANTAQ), 2015.

Entre 1995 e 2008 houve pequenas variações na movimentação de cargas pelo terminal, porém verifica-se uma queda desde 2009 (mais significativa nos anos de 2010, 2011 e 2014), devido à recessão econômica internacional e à desaceleração da economia nacional (tabela 4). Além disso, há uma preferência dos armadores em movimentar mercadorias nos portos/terminais mais modernos (equipamentos, profundidade etc.), pois possuem condições de receber maiores navios de cargas. Tal fato reduz o custo por parte dos armadores e maximiza a utilização da capacidade dos navios (substituição dos navios pequenos e médios pelos grandes conteineros, graneleiros, petroleiros e mistos).

Em geral, os produtos movimentados pelo TMIB possuem baixo valor agregado, sendo reflexo da dinâmica econômica estadual e da reduzida modernização setorial. A carência de equipamentos avançados e a falta de ampliação da área do terminal prejudicam a movimentação de bens de médio/alto valor em contêineres (tabelas 5 e 6). 
Tabela 5: Principais mercadorias movimentadas no Terminal Marítimo Inácio Barbosa (toneladas), 2014.

\begin{tabular}{c|c|c|c|c|c}
\hline \multicolumn{3}{c|}{ Longo curso } & \multicolumn{3}{c}{ Cabotagem } \\
\hline Cargas & Quantidações e Importações & Cargas & Quantidades & Cargas & Quantidades \\
\hline Cimento & 107.008 & Trigo & 86.374 & & \multirow{2}{*}{ Trigo } \\
\cline { 1 - 3 } $\begin{array}{c}\text { Fertilizantes } \\
\text { e adubos }\end{array}$ & 190.754 & $\begin{array}{c}\text { Coque de } \\
\text { petróleo }\end{array}$ & 503.554 & 35.182 \\
\cline { 2 - 4 } & $\begin{array}{c}\text { Químicos e } \\
\text { inorgânicos }\end{array}$ & 43.551 & & \\
\hline
\end{tabular}

Fonte: Agência Nacional de Transportes Aquaviários (ANTAQ), 2015.

Tabela 6: Principais produtos exportados e importados por Sergipe, 2014.

\begin{tabular}{c|c|c|c}
\hline Exportação & Porcentagem & Importação & Porcentagem \\
\hline Sucos de laranja & 62,3 & $\begin{array}{c}\text { Insumos químicos } \\
\text { (principalmente fertilizantes) }\end{array}$ & 27,3 \\
\hline Sucos de abacaxi & 8,2 & Trigo & 11,8 \\
\hline $\begin{array}{c}\text { Sucos e outros } \\
\text { cítricos }\end{array}$ & 3,4 & Coque de petróleo & 10,2 \\
\hline Açúcares & 6 & $\begin{array}{c}\text { Máquinas para fabricação de } \\
\text { recipientes de vidros }\end{array}$ & 3,7 \\
\hline Calçados & 7,8 & Aparelhos e circuitos elétricos & 4,0 \\
\hline Outros & 12,5 & Outros & 47,9 \\
\hline
\end{tabular}

Fonte: Observatório de Sergipe, 2015.

Em 2014, a movimentação portuária de cargas em Sergipe evidencia a relevância da produção de cítricos para atender o mercado nacional e internacional. Entretanto, o estado carece de um setor industrial diversificado, como bens de capital, equipamentos eletrônicos e de informática etc., sendo importante para o efeito multiplicador interno (tabelas 5 e 6 ).

A movimentação de cargas no Terminal Marítimo Inácio Barbosa (TMIB) é pouco expressiva (tabela 7), principalmente quando se compara a outros portos e terminais do país, sendo importante sua expansão e modernização para atender as demandas internas e externas. Fomentar o setor portuário e marítimo é imprescindível para o desenvolvimento regional, porém os insuficientes investimentos públicos e privados e o modelo de concessão inadequado (Estado não regulador) prejudicam a economia sergipana. 
Tabela 7: Origem e destino da cabotagem e do longo curso no Terminal Marítimo Inácio Barbosa, em 2014.

\begin{tabular}{c|c}
\hline \multicolumn{2}{c}{ Cabotagem } \\
\hline Alagoas - Sergipe & 21.412 toneladas \\
\hline Ceará - Sergipe & 25.724 toneladas \\
\hline Espírito Santo - Sergipe & 155.747 toneladas \\
\hline Rio Grande do Sul - Sergipe & 35.182 toneladas \\
\hline \multicolumn{2}{c}{ Longo curso } \\
\hline África - Sergipe & 71.482 toneladas \\
\hline América do Norte - Sergipe & 447.392 toneladas \\
\hline América do Sul - Sergipe & 216.448 toneladas \\
\hline Ásia - Sergipe & 41.592 toneladas \\
\hline Europa - Sergipe & 154.327 toneladas \\
\hline
\end{tabular}

Fonte: Agência Nacional de Transportes Aquaviários (ANTAQ), 2015.

A hinterlândia do Terminal Marítimo Inácio Barbosa (tabela 7) compreende diversos estados brasileiros, como Sergipe, Alagoas, Ceará, Espírito Santo e Rio Grande do Sul. No que tange às trocas internacionais do TMIB, estas compreendem a África, a América do Norte, a América do Sul, a Ásia e a Europa, com aumento nos últimos anos dos fluxos com a China.

As principais empresas transportadoras rodoviárias que atuam no Terminal Marítimo Inácio Barbosa são a Meta e a Flex (transportam coque), a Transparaná e a Transpampa (escoamento de ácido sulfúrico), além da Asi (trigo e fertilizantes). A manutenção do terminal é realizada por empresas e trabalhadores terceirizados: Ipiranga (pinturas), Boy Serviços Marítimos (construção civil), Mendes e Ferreira (segurança portuária) e Lenel (controle de dados e fiscalização da entrada e saída de pessoas e caminhões).

Diversos são os gargalos existentes no setor portuário de Sergipe, quais sejam: reduzidas inversões públicas e privadas, falta de modernização (instalações, softwares e comunicações), reduzida profundidade da área de atracação, necessidade de expansão de cais e berços, construção de retroárea de apoio, intermodalidade deficiente, necessidade de expandir o modal ferroviário e sua conexão com o TMIB, modelo de concessão neoliberal (Estado não regulador), planejamento voltado exacerbadamente ao modal rodoviário, entre outros.

Realizar maiores investimentos em infraestruturas de transportes é fundamental para fomentar o desenvolvimento do estado de Sergipe, baseando-se na utilização da capacidade ociosa do setor privado. Investimentos em fixos a partir da aquisição de máquinas, equipamentos e insumos do mercado interno, ou seja, se há compra de capitais da indústria 
nacional, ao invés de simplesmente importá-los, o efeito multiplicador ocorre internamente e em cadeia. Tais investimentos geram, por conseguinte, reflexos na construção civil, na indústria, na geração de empregos e renda e no aumento do consumo (KEYNES, 1982; RANGEL, 2005).

As inversões públicas e privadas em fixos no território sergipano é uma ação anticíclica, ou seja, é importante para reduzir o desemprego nas fases recessivas da economia (absorvendo, sobretudo, a mão de obra com baixa escolaridade que teria dificuldade de inserir-se em outros setores da economia) (KEYNES, 1982; RANGEL, 2005).

A transferência de recursos ociosos para o setor portuário (antiocioso) é imprescindível para o desenvolvimento econômico de Sergipe e do país, visto que estimula as interações espaciais, os investimentos do capital privado (instalação de terminais intermodais, por exemplo) e outros, gerando resultados econômicos e sociais positivos (RANGEL, 2005).

Realizar adequadas parcerias público-privadas (PPPs) é essencial para reestruturar a matriz de transportes em Sergipe e no Brasil. A "saída rangeliana" destaca a concessão de serviços públicos à iniciativa privada sob as bases de um Estado regulador (poder concedente e credor hipotecário - Projeto de Lei n. 2.569/89) e o carreamento de recursos ociosos aos setores antiociosos. Entretanto, a lei geral que regulamentou as concessões de serviços públicos no Brasil (Lei n. 8.987/95) - que recebeu o nome de Lei Fernando Henrique Cardoso - é contrária aos interesses nacionais e pautada no Estado-mínimo (RANGEL, 2005).

A proposta se baseia na transferência à iniciativa privada das empresas e serviços que se encontram estrangulados (capacidade antiociosa), isto é, com demanda por maiores investimentos (caso do setor portuário de Sergipe). Os segmentos que necessitam de maior participação do capital privado são os serviços de utilidade pública (transportes, energia e saneamento), sendo estratégicos ao desenvolvimento nacional (RANGEL, 2005; SILVEIRA, 2011).

No modelo rangeliano o Estado adquire novas funções e responsabilidades, quais sejam: poder concedente e credor hipotecário, dizer como e onde investir, estabelecimento de metas de investimentos e dos preços das tarifas cobradas, entre outros. As empresas concessionárias devem oferecer parte de seus bens em garantia (hipoteca) para que, em caso de descumprimento do contrato ou da falta de inversões, o poder público possa tomá-los e, assim, evitar prejuízos (RANGEL, 2005).

Investir em fixos, reduzir os pontos de estrangulamento e reestruturar a matriz de transportes são essenciais para arrefecer o Custo Brasil em transportes e fomentar o 
desenvolvimento de Sergipe e do país. Há uma dependência do modal rodoviário no escoamento de cargas em Sergipe, assim, a expansão das ferrovias, das hidrovias, dos portos/terminais e da intermodalidade é imprescindível para impulsionar as interações espaciais, a produção e o comércio exterior do estado.

\section{CONSIDERAÇÕES FINAIS}

A recuperação do emprego, da renda e do consumo em Sergipe e no Brasil entre 2003 e 2013 gerou, consequentemente, o incremento dos fluxos marítimos e da circulação do capital, ao mesmo tempo em que criou necessidade de aprimoramento da logística privada para mitigação dos prejuízos decorrentes dos gargalos infraestruturais e satisfação da demanda interna e externa. Aumentaram as parcerias e as relações comerciais com os BRICS, América do Sul e Central, África, Sudeste Asiático e Oriente Médio (periferia). A maior diversificação das trocas (Sul-Sul) foi/é importante para amenizar os impactos negativos da recessão econômica internacional, impulsionando o efeito multiplicador interno.

A dinâmica recente da economia sergipana gerou/gera relevantes mudanças espaciais e sociais (produção, circulação, empregos, renda, consumo etc.). Todavia, o estado possui um setor portuário obsoleto, ou seja, com reduzida modernização, eficiência e competitividade. $\mathrm{O}$ crescimento das exportações e importações de Sergipe foi/é atendido por portos de outros estados do Nordeste (Salvador/BA e Suape/PE, principalmente) Ademais, destacam-se os produtos industrializados oriundos da Bahia, Pernambuco, Rio de Janeiro, São Paulo, Santa Catarina e Rio Grande do Sul, escoados pelo modal rodoviário.

Diversos gargalos prejudicam o setor portuário de Sergipe, como a excessiva burocracia, falta de ligação ferroviária ao TMIB, modelo neoliberal de concessão, reduzidos investimentos públicos e privados, morosidade na liberação dos recursos e nas obras, falta de dragagem para aprofundamento do canal de navegação e da área de atracação dos navios, reduzida incorporação de tecnologias (portêineres, transtêineres, softwares etc.), inexistência de um plano estratégico para fomentar o setor no estado, importância de dutovias articuladas ao terminal para transporte de petróleo e derivados, entre outros.

O fomento do setor portuário de Sergipe depende de vários fatores, quais sejam: presença do Estado como agente planejador e indutor, aumentar as inversões públicas e privadas, impulsionar a modernização tecnológica, realizar adequadas concessões de serviços públicos à iniciativa privada, estimular o carreamento de recursos ociosos ao setor 
(antiocioso), expandir os financiamentos a juros baixos, assegurar reserva de mercado e reduzir os afretamentos de navios estrangeiros, expansão das encomendas da Petrobras e da Transpetro na indústria naval brasileira (offshore, cabotagem e longo curso), reduzir a burocracia, acabar com a morosidade na liberação dos recursos públicos, acelerar a realização das obras infraestruturais e expansão da multimodalidade/intermodalidade.

Essas estratégias e ações são imprescindíveis para impulsionar o desenvolvimento econômico de Sergipe, mediante a atração de indústrias, empresas e serviços diversos. Ademais, um setor portuário dinâmico significa aproveitar melhor a produção e a comercialização de produtos da Petrobras, através da expansão da cabotagem e do longo curso e da redução da dependência de outros portos do Nordeste.

O sistema marítimo brasileiro não é homogêneo. O estado de Santa Catarina possui diversos portos e terminais privados que "dividem" relativamente a demanda (desconcentração portuária), com destaque aos complexos especializados na movimentação de cargas conteinerizadas (Itajaí/SC, Navegantes/SC, Itapoá/SC e outros). Nos estados de São Paulo, Paraná e Rio Grande do Sul, verifica-se uma concentração da movimentação de mercadorias em um único porto (Santos/SP, Paranaguá/PR e Rio Grande/RS, respectivamente). No Nordeste, Pernambuco e Ceará apresentam novos complexos que estão "retirando" as cargas dos antigos portos, caso de Suape/PE e Pecém/CE. Em Sergipe, além da dependência do TMIB, este carece de ampliação e modernização para atender as demandas do estado.

\section{REFERÊNCIAS}

BRASIL. Agência Nacional de Transportes Aquaviários (ANTAQ). Dados estatísticos. Brasília, 2015.

BRASIL. Ministério do Planejamento. Programa de Aceleração do Crescimento (PAC). Dados estatísticos. Brasília, 2015.

BRASIL. Ministério dos Transportes. Dados estatísticos. Brasília, 2016.

CHOLLEY, André. Observações sobre alguns pontos de vista geográficos. In: Boletim Geográfico, v. 22, n. 179. Rio de Janeiro, 1964, p. 139-145.

CORREAA, Roberto Lobato. Interações Espaciais. In: CASTRO, I. E. de; CORRÊA, R. L.; GOMES, P. C. da C. (Org.). Explorações geográficas. Rio de Janeiro: Bertrand Brasil, 1997, p. 279-314. 
FELIPE JUNIOR, Nelson Fernandes. Circulação, transportes e logística no setor portuário e marítimo brasileiro. Vila Velha: Above, 2014.

FELIPE JUNIOR, Nelson Fernandes. Dinâmica econômica e recentes transformações no transporte marítimo de cabotagem e longo curso no Brasil: alguns apontamentos sobre a modernização portuária no Estado de São Paulo. Tese de Doutorado em Geografia. FCT/UNESP. Presidente Prudente, 2012.

FROMM, Gary (Org.). Transporte e desenvolvimento econômico. Rio de Janeiro: Victor Publicações, 1968.

FURTADO, Celso. Dialética do desenvolvimento. Rio de Janeiro: Fundo de Cultura, 1964.

KEYNES, John Maynard. A teoria geral do emprego, do juro e da moeda. São Paulo: Atlas, 1982.

MARX, Karl. O capital: crítica da economia política (livros 1 e 2). Rio de Janeiro: Civilização Brasileira, 2005.

MIGLIOLI, Jorge. Acumulação de capital e demanda efetiva. São Paulo: Hucitec, 2004.

RANGEL, Ignácio. Obras reunidas (vol. 1 e 2). Rio de Janeiro: Contraponto, 2005.

SANTOS, Milton. A natureza do espaço: técnica e tempo, razão e emoção. São Paulo: Edusp, 2002.

SANTOS, Milton; SILVEIRA, María Laura. O Brasil: território e sociedade no início do século XXI. Rio de Janeiro/São Paulo: Record, 2001.

SILVEIRA, Márcio Rogério. As cinco revoluções e evoluções logísticas e seus impactos sobre o Brasil. In: LAMOSO, L. P.; MOURÃO, P. F. C.; SILVEIRA, M. R. (Org.). Questões nacionais e regionais do território brasileiro. São Paulo: Expressão Popular, 2009.

SILVEIRA, Márcio Rogério (Org.). Circulação, transportes e logística: diferentes perspectivas. São Paulo: Outras Expressões, 2011. 